\title{
Gingival health status among patients with transfusion dependent thalassemia (TDT) in Erbil city
} \begin{abstract}
Dildar A. Othman *
Omer Surchi**

Othman A. Omer***

\section{Abstract}

Background and objective: Thalassemias constitute a form of anemia that has clear problems in relation to oral health. The purpose of this study to determine whether beta thalassemic disease is associated with increased risk of gingival disease.

Methods: In this case control study, 50 transfusion dependent thalassemic patients aged 12 to 24 years compared with 50 healthy control subjects matching in age and sex. At beginning both beta thalassemic patients and healthy control subjects were receiving scaling and polishing with good oral hygiene instruction and using the same tooth paste and tooth brush in order to obtain zero score at base line. Then, the all subjects were followed up for six month at one week (base line), one month, three months and six months interval. Gingival health status was assessed through these six months by application of Silness and Loe plaque index (PI), Ramfjord calculus index (Cal I) and Loe and Silness Gingival index (GI). Data were analyzed by using chi square, fisher's exact test, student t-test and paired t-test.

Results: At base line, results showed that plaque index and gingival index were higher among beta thalassemic patients than healthy control subjects with no statistical significance difference. Regarding the calculus index, there was no calculus in both groups at base line. After six month follow up (one, three and six month interval) results showed that plaque index, calculus index and gingival index were higher among beta thalassemic patients than healthy control group with statistically significant difference $(P<0.05)$.

Conclusion: Patients with beta thalassemic major showed significant difference in their gingival health status and therefore a special oral hygiene care program needed for this target group.
\end{abstract}

Keywords: gingival disease, transfusion dependent thalassemia, plaque index, calculus

\section{Introduction}

Thalassemias are a diverse group of genetic blood diseases characterized by absent or decreased production of globulin protein chains of the hemoglobin molecule, resulting in microcytic anemia of varying degrees. Based on their clinical and genetic orders, thalassemias are classified mainly into major (homozygous) and minor (heterozygous) type. Thalassemia major ( $\beta$ -thalassemia), or Cooley's anaemia, exhibits the most severe clinical symptoms while thalassemia minor is mild and considered to be clinically asymptomatic. An intermediate form of thalassemia may also occur ${ }^{1,2}$.
Thalassemia is a disease which not only affects the patient but also leaves a devastating psychosocial effect on the family of the patient. Furthermore, frequent blood transfusion is very expensive, preventive and restorative dental care programmes as well increase financial burden on societies ${ }^{3}$. Thalassemia is most in Mediterranean, middle and Far East Asia, in Iraq, the total number of thalassemic patient was nearly 5000 according to record of ministry of health for the year $2003^{4}$. Among Kurdish people in Erbil city thalasssenic patient are about 560 according to the records of the thalassemia center in

*Department of Periodontology, Specialized dental polyclinic, Directorate of Health, Erbil, Iraq

$* *$ Department of Oral Diagnosis , College of Dentistry, Hawler Medical University, Erbil, Iraq

$* * *$ Department of Oral and Maxillofacial Surgery, College of Dentistry, Hawler Medical University, Erbil, Iraq 
Erbil city for the year 2011. $\beta$ - thalassemia major is the most severe congenital hemolytic anemia. At 6 month of life the first clinical manifestations appear. The hematocrit decreases to less than $20 \%$, the degree of anemia can reach a hemoglobin level of 2 to $3 \mathrm{~g} / \mathrm{dl}$, and the hemolysis is extensive, as is the iron over load ${ }^{5}$. The oral mucosa is pale or lemon yellow color due to anemia and deposition of billirubin pigment ${ }^{6}$. Growth and development in children is slow. In adolescence, secondary sex characteristics are delayed. The skin color becomes Ashen-gray due to the combination of pallor, jaundice, and hemosiderosis. $\mathrm{Pa}$ tient also presents cardiomegaly, hepatomegaly and splenomegaly ${ }^{7}$. There is little study about the prevalence of gingival disease in $\beta$ thalasssenic patient in Erbil study. Since this genetic disorder is more in our region; periodontal and gingival study is necessary to allow setting preventive dental and periodontal programs for these medically compromised patients.

\section{Methods}

The sample size were 100 individuals, they include two groups; the first group was 50 (25 male and 25 female) clinically proved cases of transfusion dependent thalassemia attending for regular blood transfusion in the thalassemic center in Erbil city. The second group include 50 age and sexmatched healthy individuals from the same area [relative of the patients in an attempt to have matched age, sex, socioeconomic status and general dental care background] was selected as the control group, they were free of thalassemia both the major and minor forms. The age of both study and control groups ranged from 12 to 24 years old. The consent was obtained from individuals or their parents (guardians) in both study and control group to include them in this study. Then all the subjects including study and control group were receiving scaling and polishing in the Brayeti family health center in Erbil city with good oral hygiene instruction and using the sametooth paste and same tooth brush in order to obtain zero score at base line. Then after one week all the subjects were examined to measure the indices which included plaque index and gingival index. Then they were followed up at one month, three months and six months by examining plaque index, calculus index and gingival index according to American dental association guideline (council on dental therapeutics, 1985). The data collection was from December 25th 2010 to July 25th 2011. The data was obtained by a direct interview with the patients themselves; the case sheet was designed by the researcher. Each subject was examined intra -orally to check the fulfillment of the required Sample selection criteria. All patients were examined by one examiner to measure the dental plaque following the criteria of Silness and Löe $(1964)^{8}$. Six index teeth were involved Ramjord teeth. In this study four surface of each tooth were examined including mesial, buccal, distal and lingual surfaces. Measuring dental calculus utilizing the criteria of Ramfjord $(1959)^{9}$. The six index teeth were examined only. The gingival condition was also examined following the criteria of Löe and Silness $(1963)^{10}$.

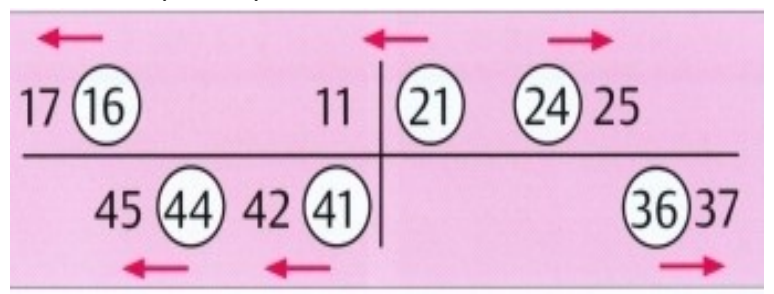

Figure 1: Löe and Silness criteria

\section{Statistical analysis}

Data were entered and analyzed using the Statistical Package of Social Sciences (SPSS, version. 18). Data are summarized and appropriate tables showing different variables are demonstrated. Chi-square test of association was used to find out associations (relations) between different independent index (Plaque, calculus and gingival) among cases and controls. When Chi-square is inappropriate, Fisher's Exact Test was used. Unpaired student t-test was 
used to analyze the differences between the means of indices. Paired t-test was used to compare between means on indices at base line, first month, third month and sixth month. P-value equal and less than 0.05 was considered as statistically significant.

\section{Results}

The age of both group ranged from 12-24 years old with mean $\pm S D$ of $15.9 \pm 3.439$ years. Table 1 , shows no significance difference between the two groups regarding age. At base line the dental plaque of $98 \%$ of beta thalassemic patients and $100 \%$ of controls were between $0.1-1$ with no statistical association between beta thalassemic patients and controls $(P=1.00)$. While after follow up 1,3 and 6 months the result changed significantly and revealed that the plaque value among beta thalassemic patients was higher than control group and the difference was statistically significant $(P<0.001)$ as shown in figure 2 . Regardind dental calculus results showed no calculus was present neither in transfusion dependent thalassemic patients nor in healthy group at base line but it started to appear after one month in which $42 \%$ of the beta thalassemic patients had dental calculus and started to increase to be $44 \%$ at third month and $50 \%$ at six months. In healthy control group the prevalence of patients presents with calculus at one month, three month was zero and at six months was $4 \%$. the difference statistically was significant $(P<0.001)$ as shown at figure 3 .

Table 1: Comparison of mean age between study and control group

\begin{tabular}{lllllll} 
& Groups & $\mathrm{N}$ & Mean age & $\pm S \mathrm{D}$ & t-value & p-value \\
\hline \multirow{2}{*}{ Age } & Thalassemia & 50 & 16.20 & 3.70 & & \\
& healthy & 50 & 15.66 & 3.17 & 0.784 & 0.435
\end{tabular}

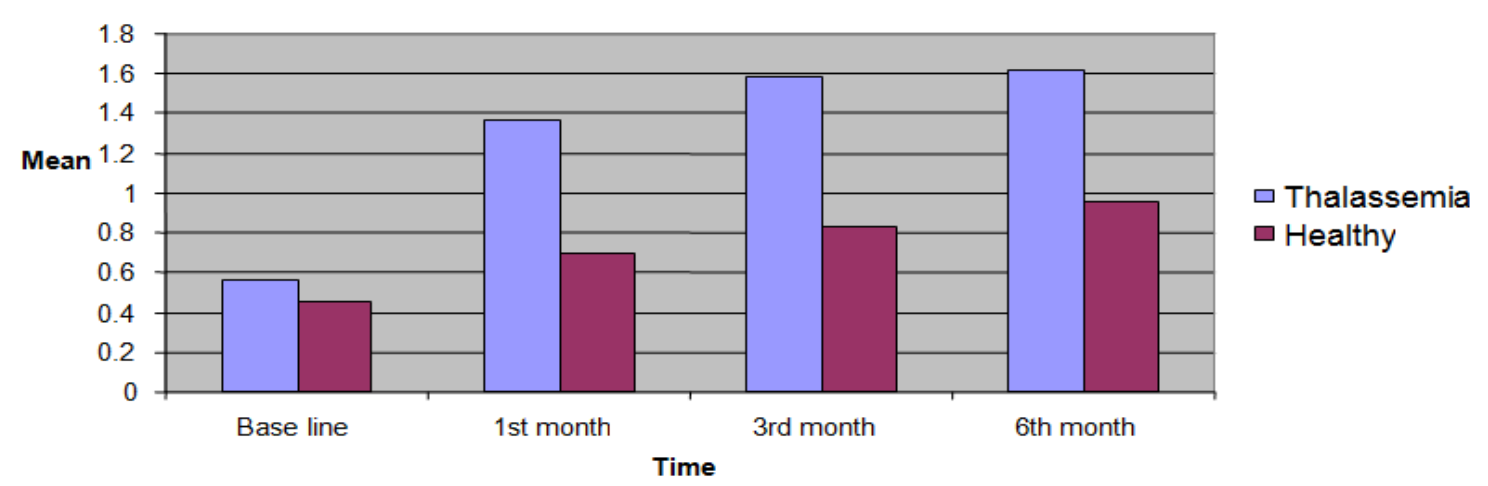

Figure 2: Differencein plaque index at base line, one month, three month and six month follow up between thalassemia and healthy groups. 


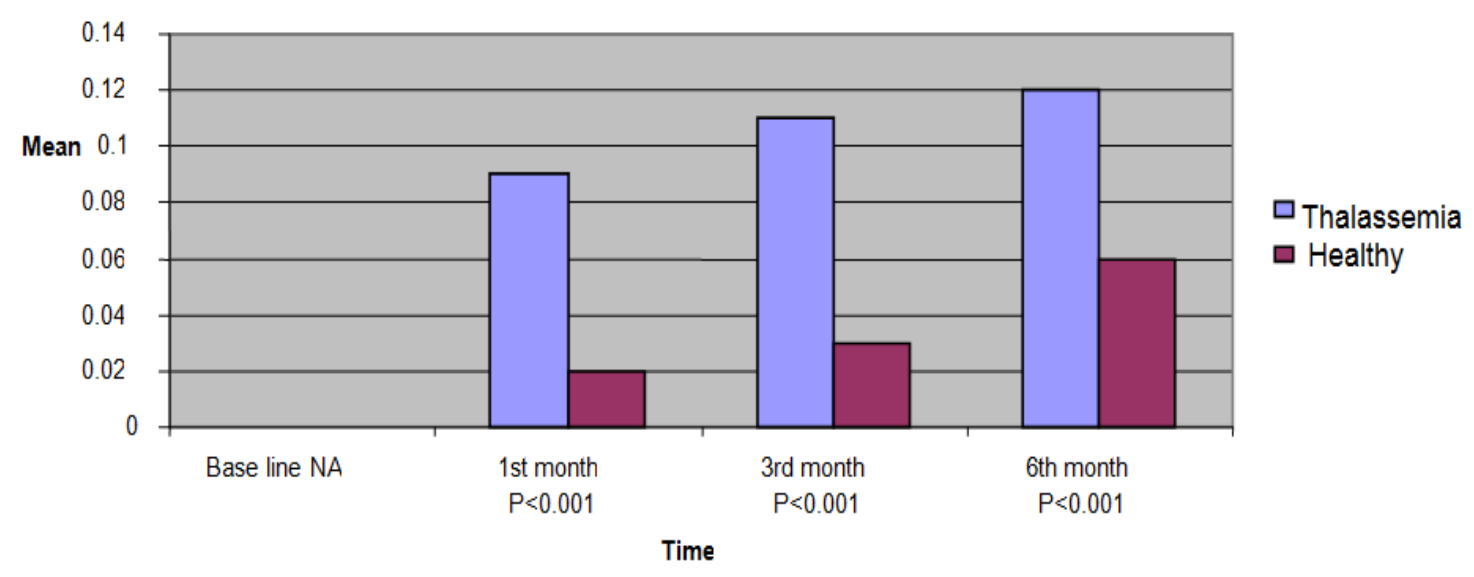

Figure 3: Difference in calculus index at base line, one month, three month and six months follow up between thalassmia and healthy group.

Regarding gingival index at base line the results showed that $94 \%$ of transfusion dependent thalassemia has mild gingivitis and $100 \%$ of healthy group has mild gingivitis and $6 \%$ of transfusion dependent thalassemia has moderate gingivitis, this association statistically was not significant $(P=0.24)$. At first month the results showed that $100 \%$ of transfusion dependant thalassemia has moderate gingivitis and $24 \%$ of healthy group has moderate gingivitis and $76 \%$ has mild gingivitis. At third month results showed that $94 \%$ of transfusion dependant thalassemia has moderate gingivitis and $6 \%$ has mild gingivitis, while among healthy group $34 \%$ has moderate gingivitis and $66 \%$ has mild gingivitis. At sixth month $100 \%$ of transfusion dependant thalassemia has moderate gingivitis and $42 \%$ of healthy group has moderate gingivitis and 58 have mild gingivitis, the difference statistically was significant $(P<0.05)$, as shown at figure 4 .

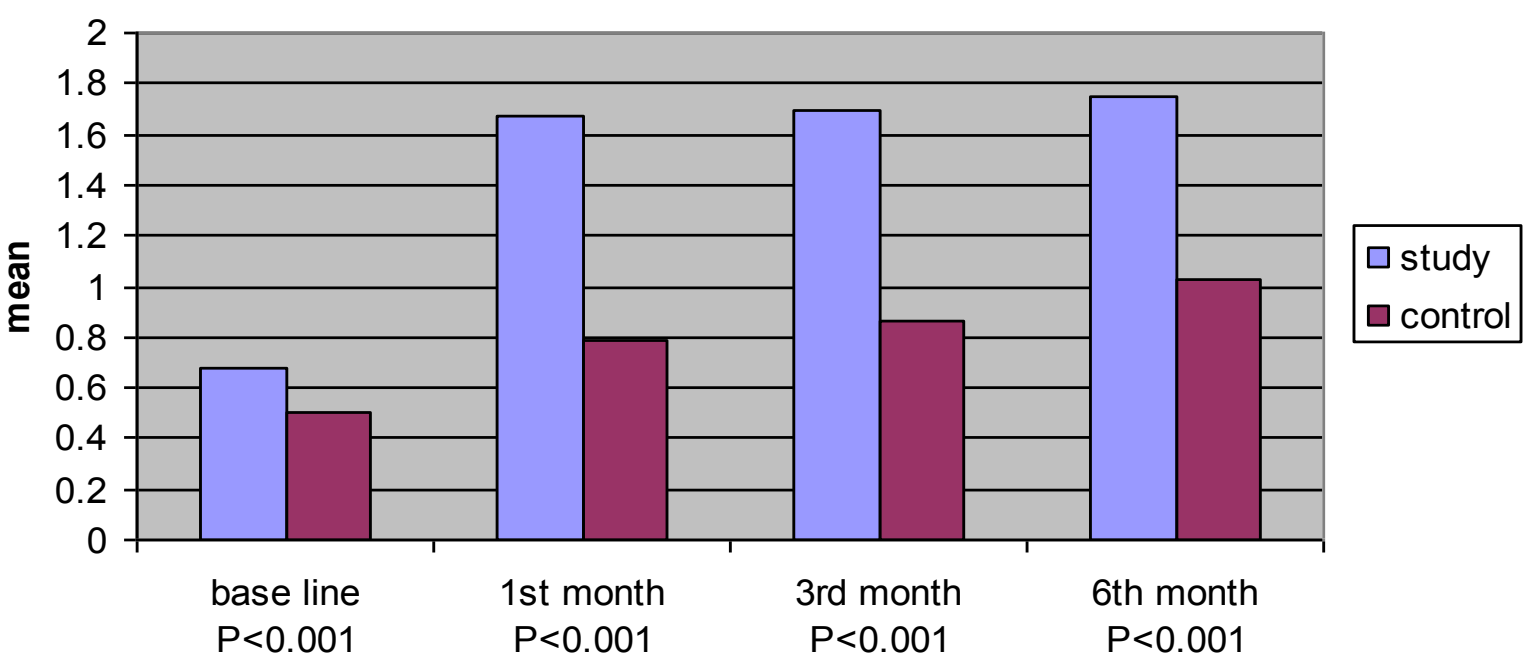

Time

Figure 4: difference in gingival index at base line, first month, third month and sixth month between thalassemic and healthy group 


\section{Discussion}

At base line the results showed that plaque value among beta thalassemic major patients were higher than control group but the association was not significant. After follow up (one, three and six month interval) results changed and showed that plaque index among beta thalassemic patients was higher than control group and the difference statistically was significant. These results were in agreement with Mohammed $^{4}$, Ghasempour et $\mathrm{al}^{11}$, Saeed et $\mathrm{al}^{12}$ and $\mathrm{Al}$ Jobouri and $\mathrm{Al}$ Casey $^{13}$ and disagree with Al Mashadany ${ }^{14}$, Scutellari et $\mathrm{al}^{15}$, Luglie et $\mathrm{al}^{16}$, Al Wahadni et $\mathrm{al}^{3}$ and Mehdizadeh et $\mathrm{al}^{17}$. This high incidence in plaque index among beta thalassemic patients is related primarily to dental neglecting and the patients are more concerned about their serious physical problem and pay lesser attention to dental care except when they have a dental problem they may seek dental advice ${ }^{8}$. Another explanation for high incidence of plaque indexamong beta thalassemic patients may be related to the maxillofacial characteristic of thalassemic patient such as extreme malocclusion, crowding, maxillary over jet which has been studied by several investigators $3,8,18,19$. At base line results showed that there was no calculus in neither beta thalassemic patients nor in control group but after follow-up ( one, three and six month interval) results changed and showed that calculus index among beta thalassemic patients were higher than control group and the difference statistically was significant. These results were in agreement with Mohammed $^{4}$, Ghasempour et $\mathrm{al}^{11}$, Saeed et al and Al Jobouri and Al Casey ${ }^{13}$ and disagree with Scutellari et $\mathrm{al}^{15}$ and Luglie et $\mathrm{al}^{16}$. This high incidence of calculus index among beta thalassemic patients primarily related to plaque accumulation on the tooth surface and dental neglecting by the patients ${ }^{20}$. Another explanation for higher amount of calculus index among beta thalassemic patients may be due to dental characteristic of thalassemic patient such as crowding, extreme malocclusion and increase over jet ${ }^{3,8,19}$. At base line the gingival index was higher among beta thalassemic patients than control group but this association was not significant. After the follow-up periods, one, three and six month interval, the results were changed and showed that gingival index among beta thalassemic patients were higher than control group and the difference was statistically significant. These results were in agreement with Siamopoulu-Mavridou et $\mathrm{al}^{21}$, Al Mashadany ${ }^{14}$, Mohammed4, Ghasempour et $\mathrm{al}^{11}$, Saeed et $\mathrm{al}^{12}$ and $\mathrm{Al}$ Jobouri and $\mathrm{Al}$ Casey $^{13}$ and disagree with Scutellari et $\mathrm{al}^{15}$, Al Wahadni et $\mathrm{al}^{3}$, Luglie et $\mathrm{al}^{16}$ and Mahdizadeh et $\mathrm{al}^{17}$. While regarding the high incidence of gingival disease among beta thalassemia patients is related to the poor oral hygiene, bacterial plaque accumulation on the teeth and gingival surface which is the major etiological factors for the development and maintenance of gingivitis ${ }^{20}$. Another explanation of high prevalence of gingivitis is correlated to the maxillofacial characteristic of thalassemic disease; potential relation ship between plaque accumulation and mal occlusion such as crowding, extreme over jet which has been studied by several studies 3,19. In addition drying of the gingiva through the patient's inability to close their mouth over the protruding teeth, mouth breathing with chronic anorexia may in some case predispose to gingival disorder $20,22,23$. Thalassemic patient had skeletal class II mal occlusion might affect the gingival ${ }^{4,24}$. In patients with beta thalassemia an increased incidence of infection was noted due to certain immunological abnormalities that had been reported among them ${ }^{25}$. in addition desferioxamine which is used in the treatment of beta thalassemic patients impair cell mediated immunity $26,27,28$. further more the saliva concentration of phosphorous, lysozyme and IgA were significantly lower in the beta thalassemic patients. These finding could provide an explanation for the higher gingivitis observed among thalassemic patients ${ }^{21}$. 


\section{Conclusion}

The results of this study reveals significant difference between beta thalassemic patients and healthy sample after six month of follow up in plaque index, calculus index and gingival index.

\section{References}

1. Schrier SL. Pathophysiology of thalassemia. Curr Opin Heam 2001; 9(2):123-6

2. Scott J. Hematology. In: Behrman R, Kliegman R editors. Essentials of pediatrics. 4th ed. Saunders Company:Philadelphia 2002: 605-43.

3. Al-Wahadni AM, Taani DQ, Al-Omari MO. Dental diseases in subjects with $\beta$-thalassaemia major. Community Dent Oral Epidemiol 2002; 30: 41822.

4. Mohammad IJ. Oral health status, treatment need and dentaofacial anomalies among 5-14 years patient with beta thalassemia major syndrome in comparison to school children in Baghdad prvience. M.Sc thesis. College of dentistry, University of Baghdad. Iraq2004.

5. Braun W, Antony S, Kasper, Hauser, Longo, Jameson. Harrison's principle of internal medicine. $15^{\text {th }}$ ed. New York, Me Grow Hill 2001; 66674

6. Greenberg M S. Burket's oral medicine. $10^{\text {th }}$ ed. Philadelphia, Lippincott 2003. 430-36

7. Salehi MR, Farhud DD, Tohidast TZ, Sahebjamee M. Prevalence of Orofacial complications in Iranian Patients with $\beta$ thalassemia major. Iranian J Pubi Health 2007; 36(2): 43-3.

8. Silness J, Roynstrand T. Effects of dental health of spacing of teeth in anterior segments. J Clinic Perio 1984; 11:387-98

9. Ramfjord SP. Indices for prevalence and indices of periodontal disease $\mathrm{J}$ perio 1959; 30: 51-2

10. Loe H, Silness J . Periodontal disease in pregnancy: prevalence and Severity. Acta Odontologica Scandinavica 1963; 51: 533-18.

11. Ghasempour $M$, Pouramir $M$, Hagahmadi $M$, Tamadoni A, Myrzaei N.Oral condition, chemistry of saliva in thalassemic patients. Int $\mathrm{J}$ of Pediatr Dent 2005; 15(2): 33-83

12. Saaed, Lamia M, Vian O. Oral health and dentofacial anomalies among beta thalssemia major in Erbil city, Iraq. AIP conference proceedings 2010; 1229:42-8.

13. Al-Joubory HS and Al Casey M. Selected salivary constituents among $16-18$ years patients ith $\beta$ thalassemia major in relation to oral disease. $J$ agh College Dentistry 2011; 23(2): 124-127.

14.Al-Mashhadany BA. Periodontal health status and Thalassemia Major A clinical study. M.Sc thesis1994. College of dentistry, University of Baghdad.

15. Scutellari PN,Orzincolo C, Andraghetti D, Gambrini MR. Anomalies of the masicatory apparatus in the beta thalassemia. The present status after transfusion and iron chelating therapy. Radiol Med 1994; 87(4): 389-96.

16. Luglie PF, Campus G, Deiola C, Mela MG, Gallisai $D$. Oral Condition chemistry of saliva and salivary levels of streptococcus mutans in thalassemic patients. Clin Oral Inves 2002; 6(4): 223-6.

17. Mehdizadeh MA, Mehdizadeh MO, Zamani G. Orodental complication in patients with major beta-thalassemia. Dent Res J 2008; 5(1): 17-20.

18. Ashley FP, Usiskin LA, Wilson RF, Wagaiyu E. The relation ship between irregularity of the incisor teeth, plaque and gingivitis: a study in agroup of school children aged 11-14 years. European J of orthodontics 1998; 20: 65-72.

19. Patil S. Clinical and radiological study of orofacial manifestation in thalassemia. A M.Sc thesis 2008. Rajiv Gandhi University of Health Sciences, Karnataka and Bangalore.

20. Siamopoulou-Mavoidou A, Movridis A Galanakis E, Vasakos S, Fatourou H, Lapatsanis P. Flow rate and chemistry of parotid saliva related to dental caries and gingivitis in patients with thalassaemic major. Int J Pediatr Dent 1992; 2(2): 93-7.

21. Kalpan RI, Werther R and Castano FA. Dental and oral findings in Cooley's anemia: A study of fifty cases. Ann N.Y. Acad Sci 1964; 119: 664-6.

22. Proffit WR, Fields HW, Ackerman JL, Bailey LJ, Tulloch JF.Contemporary orthodontics. $3^{\text {rd }}$ ed. Mosby 2000: 1-22.

23. Bhalajhi SI, Lyyer BS .Orthodontics. The art and science. 3rd ed. Arya (Medi) 2004;55-5.

24. Amini F, Jafari A, Eslamian L, Sharifzadeh S . A cephalometric study on craniofacial morphology of Iranian children with beta thalassemia major. Orthod Craniofacial Res 2007; 10: 34-4.

25. Wilton J, Griffiths G.S, Curtis M.A, Maiden M.F.J, Gillette I.R, Wilson P.T et al . Detection of high risk group and individuals for periodontal disease. J Clin Period 1987; 15: 339-46.

26. Musumeci G, Schilirom A, Romeo A, Sciotto A, Rosalba, Pizzarelli G. Lymphocyte change in thalassemia major. Arch Dis Childhood 1979; 54: 954-7.

27. Lederman H, Cohen A, Lees F, Gelfand G. Desferoxamine a reversible $S$-shape inhibitor of human lymphocyte proliferation. Blood 1984; 64: 748-84.

28. Dwyer J, Wood J, Mcmamara A, Andiman, Linda $\mathrm{R}$, Theresa $\mathrm{O}$ et al. Abnormality in immune system in children with beta thalassemia major. Clin Exp Immunol 1987; 68: 621-29. 